\title{
VOICE OF EDITORS
}

\section{Not-for-Profit Journal Quality/Ranking Lists or For- Profit Journal Indexing: What is a Better Choice?}

\author{
${ }^{*}$ Ch. Mahmood Anwar

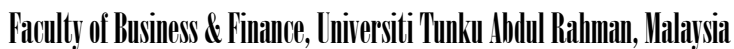

It has become a common trend among academic professionals to check listing/ranking of academic journals in recognized journal ranking/quality lists before submitting their articles for review and possible publication. In addition, professional research evaluation committees in universities often consult many quality journals ranking lists. Although a majority of scholars/institutions consider forprofit indexing/abstracting databases like SSCI, SCI, Scopus, IBSS, PsycINFO etc. to assess quality of journals, this article focuses on the not-for-profit academic journal quality/ranking lists developed by various institutions or governments. This editorial presents a review of select journal quality lists produced by not-for-profit organizations because academic products developed by for-profit companies always reflect some degree of bias (Krimsky, 2013). Therefore, the lists/rankings like Clarivate Analytics (formerly Thomson Reuters) journal ranking, Cabell's journals list, SCImago journal ranking (although it is free but it harvests data from for-profit database Scopus) will be excluded.

There are various academic journal ranking lists available in the market. For instance, Google Scholar provides a free list of top 100 multidisciplinary publications (Google Scholar, n.d.). This list is based on h5-index. Publications having higher h5-index are ranked higher. This list may be useful for scholars but has a very limited scope because it is not possible for every research scholar to publish in these top 100 publications. Secondly, this list excludes (or journals in these areas may not have reached to the desired h5-index value) many science and art areas for example, fine arts, music, astronomy, business, management etc. Similarly, Financial Times (FT) also calculates academic journal rankings and provides a list of top 50 academic journals for free (Ormans, 2016). Again, the scope of this list is limited because it only provides 50 journals in the areas of management and business. Hence, FT journal list is not very useful for scholars from other academic disciplines just like Google Scholar's top publication list. The French Foundation for Management Education (FNEGE), University of Sydney Business School, and Australian Research Council's (ARC) Excellence in Research for Australia (ERA) also maintain their journal quality lists. In addition, Agence d'Évaluation 
de la Recherche et de l'Enseignement Supérieur (AERES), Centre National de la Recherche Scientifique (CNRS,) and Qualis journal quality/ranking lists are used in France and Brazil (Vogel, Hattke and Petersen, 2017). However, these lists did not gain global popularity.

After background development, a review of top 10 academic journal quality/ranking lists, developed by not-for profit organizations or governments, is presented below. These lists have their own limitations as well, but they are frequently used at regional and/or international level. In this article, the top 10 ranking is provided on the basis of versatility, subject coverage, value added features, and international usability.

\section{Norwegian Register for Scientific Journals, Series and Publishers}

The Norwegian Register for Scientific Journals, Series and Publishers is operated by National Board of Scholarly Publishing (NPU) and Norwegian Centre for Research Data (NSD) on behalf of the Norwegian Ministry of Education and Research (Norwegian Centre for Research Data, 2020). This list divides academic journals into two levels. Level 1 represents the journals practicing standard peer review and quality control, whereas level 2 represents high standing journals. The NSD editors/reviewers focus on the external review process, configuration of editorial board, and international authorship of the journals for inclusion in the list. This versatile scholarly resource enlists quality academic journals publishing in the areas of science and art. Norwegian Register is a truly heterogeneous journal quality/ranking list covering even less demanded subject areas of academic publications like music, astronomy, and fine arts. Norwegian Register is considered as a reliable academic resource across all Nordic and European countries. The list is also used in South Africa and in few Russian regions for academic research evaluation by universities.

The Norwegian Register not only provides the ranking of journals but also furnishes information about journals' peer review status, authorship background, and archiving policy (SHERPA/RoMEO). In addition, with the rising demand of open access publications, the register also provides information about authenticity of open access journals. First, it checks if the journal is included in Directory of Open Access Journals (DOAJ), if a journal is not listed in DOAJ than the Norwegian Register uses the NSD's open access verification service to verify an open access journal. The Norwegian Register excellently utilizes NSD's another prestigious and respected database ERIH PLUS data to provide these additional features. No doubt, these additional services are very helpful for scholars and enhance the reliability and utility of a journal quality/ranking list. This makes The Norwegian Register a value-added journal quality/ranking list.

\section{Chartered Association of Business School's (CABS) Academic Journal Guide}




\section{Anwar}

The Academic Journal Guide (AJG) is produced and maintained by Chartered Association of Business School (CABS), UK. CABS announces call for academic journal suggestions related to business, management, and allied areas every three years (Chartered Association of Business Schools, 2020). The list is updated after 3 years; updates include inclusion/exclusion of journals based on suggestions from the international scholars. The AJG's editors/reviewers use both qualitative and quantitative indicators for selection of journals. This list ranks the journals by assigning following categories: A* (Journals of distinction), A (journals publish the most original and best-executed research), 3 (journals publish original and well executed research papers and are highly regarded), 2 (journals publish original research of an acceptable standard), and 1 (journals publish research of a recognized, but more modest standard). The ABS Academic Journal Guide 2015 edition ranked 1401 academic journals, whereas Academic Journal Guide 2018 edition ranked 1561 academic journals.

Though limited to business related areas, this list has been developed not only for the UK, it is a truly useful international resource because ABS officials mentioned in ABS Academic Journal Guide 2015 edition's methodology section, point IV, that "the Guide should be comprehensive in the coverage of research conducted in business schools internationally, covering a wide range of disciplines, fields and sub-fields within the social sciences and taking an inclusive approach to what constitutes business and management research" (Association of Business Schools, 2015). Hence, it can be deduced that ABS Academic Journal Guide (AJG) is equally useful for business schools in the UK and the rest of the world due to its international scope and nature.

\section{CARHUS Plus +}

CARHUS Plus + is a system used to evaluate scientific journals, in the fields of social sciences and humanities, published locally, nationally or internationally. The list was developed by the Spanish Agency for Management of University and Research Grants (AGAUR) and commissioned by the General Directorate for Research, Spain. This journal quality list is reviewed and updated every two years (Agency for Management of University and Research, 2018a).

In the current list (CARHUS Plus+, 2018), 6233 journals have been evaluated and included. The number of journals is expected to grow in the new list expected to launch in 2021. The list divides journals into group $A$, group $B$, group $C$, and group $D$. The editors evaluate the journals on the basis of their indexing status in ERIHPLUS, Social Sciences Citation Index, Arts \& Humanities Citation Index, Science Citation Index, and Scopus. Editors of the list also look at editorial board, article evaluation process, affiliations of authors, periodicity, instructions to authors, and Source-Normalized Impact per Paper (SNIP) or The Secondary Diffusion Index (ICDS - Índex Compost de Difusió Secundària) value of the journal to determine its group. The ICDS value of journals is a new alternative to a journal's 
impact factor. The ICDS indicator was developed by research group of the Faculty of Biblioteconomy and Documentation, University of Barcelona, Spain, headed by Dr. Cristóbal Urbano. The ICDS is an indicator that measures the diffusion of journals in scientific databases.

New journals can be proposed by the publisher of a journal or faculties of European/international universities by sending a request to AGAUR accompanied by a current report explaining how subject journal addresses the guidelines for scientific publication determined by AGAUR. The report must explain how the parameters mentioned in the section "How are A, B, C and D journals classified?" are complied with, must mention type of the peer review system applied to determine quality of published articles, and the percentage of rejected articles (Agency for Management of University and Research, 2018b). New journal proposal must be supported by three professors from different international universities. CARHUS Plus + is accepted in Spain and some other European countries. Nonetheless, it is not popular compared to ABS list or Norwegian Register.

\section{Australian Business Deans Council (ABDC) Journal Quality List}

ABDC journal quality list was developed by Australian Business Deans Council in 2007 to overcome the regional and discipline bias of international journal quality lists produced by various international entities. The list was updated in year 2009, 2013, 2016, and 2019. The list divides journals into 4 categories i.e., $A *$ (represents approximately the top $5-7 \%$ of the journals), $A$ (represents approximately the next $15-25 \%$ of the journals), B (represents approximately the next $35-40 \%$ of the journals), and $C$ (represents the remaining recognized quality journals) (Australian Business Deans Council, 2019).

This list is limited to business related journals only. The second major limitation is, it was developed to serve the interests and needs of ABDC members and the business-related academic community located in Australia and New Zealand (ANZ). The third limitation is, only Australian and New Zealand (ANZ) scholarly community is allowed to propose new journals for evaluation (Australian Business Deans Council, 2016). It makes difficult for publishers outside ANZ region to propose their journals for evaluation. It is also not rational and ethical to ask an ANZ based academic body or faculty member to propose journals publish outside ANZ region. These issues with ABDC list make its scope limited to ANZ region, hence, ABDC journal quality list is not useful for business schools located outside ANZ.

\section{The Publication Forum (JUFO)}

The Publication Forum (JUFO) is a rating and classification system developed by the Federation of Finnish Learned Societies (TSV) to support the quality assessment of Finnish research outcomes (Federation of Finnish Learned Societies, 2020). To account for different publication cultures and 


\begin{abstract}
Anwar
characteristic of various academic disciplines, the list includes academic journals, book series, conferences, and book publishers. The list divides major foreign and domestic publication channels of all disciplines into three-level classification ratings i.e., 1 (basic level), 2 (leading level), and 3 (highest level).

Since 2015, the list has been used as a quality indicator for the research outcomes produced by universities within the university funding model established by the Finnish Ministry of Education and Culture. The mentioned objective of this list is to encourage Finnish researchers and academicians to publish their research articles in high-level domestic and foreign publication outlets (Federation of Finnish Learned Societies, 2021). Any publisher outside Finland can suggest new journals for inclusion. This list is limited to Finland and is not used in other countries (except Nordic countries) as a major journal quality/ranking list.
\end{abstract}

\title{
6. The Bibliometric Research Indicator (BFI) List
}

The BFI list was developed in year 2008 by Ministry of Higher Education and Science, Denmark and is maintained by their academic committee. The ministry publishes 2 lists i.e., publishers list and series list. In this article information about BFI series list is presented (Danish Agency for Higher Education and Science, 2021).

The BFI list of series is managed based on recommendations from 67 Expert Panels composed of researchers appointed by different Danish universities. Research professionals can publish in any publication outlet regardless of their subject area association. The BFI list is used to distribute funding at the university level amongst four major fields of sciences: social sciences, humanities, natural and technical sciences, and medical and health sciences.

Any publisher outside Denmark can propose new academic journals for inclusion in BFI list. Only Danish universities receive BFI points, as they are the only institutions that are part of the funding scheme. The BFI listed journals are ranked at three levels: 1 (ordinary journals), 2 (distinguished journals), and 3 (most excellent and prestigious journals). The list is updated every year. This list is also limited to Denmark and Nordic countries. It was not developed for international research scholars as a reference academic journal quality/ranking resource.

\section{The Nordic List}

It is mentioned previously that Finland, Denmark, and Norway maintain their own journal quality/ranking lists. In 2013, Nordic authorities decided that the Nordic countries should cooperate to develop a common list of publications (Norwegian Centre for Research Data, 2019). The list would consist of a common bibliographic dataset on the publication channels listed in 3 countries' national journal quality 
lists. The plan is to join the lists technically in a cloud system by assigning all of the Nordic countries common duties to contribute to the list and equal rights to use it.

This list is developed by Norwegian Centre for Research Data (NSD), whereas the Norwegian Association of Higher Education Institutions (UHR) reports to NordForsk that is financing the project of common list. The following are the stakeholders of the Nordic List: Denmark, Finland, Norway, Sweden, Iceland, and Faroe Island. Although the Nordic List is under development, it is expected that it will provide a fruitful combination of 3 national level lists operated by Denmark, Finland, and Norway. This list is intended to be developed only for the Nordic countries.

\section{ANVUR Journals' Classification}

This journal quality list is developed and maintained by Italian National Agency for Evaluation of the University System and Research (ANVUR) (Italian National Agency for the Evaluation of the University and Research Systems, n.d.). The list divides academic disciplines into 14 major areas e.g., mathematics \& informatics, physics \& chemistry, earth sciences, biology \& medicine, agriculture \& veterinary science, civil engineering \& architecture, industrial \& information engineering, antiquities, philology, literary studies \& art history, history, philosophy, pedagogy \& psychology, law studies, economics \& statistics, political \& social sciences.

The editors of this list evaluate the suggested journals on the basis of bibliometric and peer review methods. This journal quality list is used only in Italy and serves as a resource to distribute research funding among Italian research community. Although ANVUR journal quality list cover wide subject areas, its use is limited because it was not developed for international research scholars.

\section{Harzing Quality Journal List}

This list was developed by Anne-Wil Harzing in the year 2000 (Harzing, 2020). She is a Professor of International Management at Middlesex University, London. This list is published primarily to assist researchers to target journals of an appropriate standard. Only journals publishing in areas of Economics, Finance, Accounting, Management, and Marketing are evaluated. This list also provides rankings from other journal quality lists like ABS, ABDC, HEC Paris etc.

The list follows 1-4-point ranking, assigning 4 to highest quality journals. This journal quality/ranking list is used by many Australian and European researchers and universities; however, this list is not considered as internationally recognized and utilized publication.

\section{VHB-JOURQUAL}

VHB-JOURQUAL is a journal rating system developed and published by the German Academic 
Association for Business Research (VHB) in 2003 (German Academic Association of Business Research, 2019). The German business research community called to develop this list with a view to improve the possibilities of evaluating the quality of journals. It is claimed that this list increases transparency and improves orientation.

The updates have been published in year 2008, 2011, and 2018. The latest version of the list is called VHB-JOURQUAL3. The editors of the list define scientific quality of a journal as "the degree to which the journal in question advances business research as an academic discipline". The journal evaluation is based on an overall subjective assessment (e.g., individual experiences as an author, experiences of review processes, articles read, discussions with colleagues etc.). According to the list administration, the rating expresses the perception of a journal's academic quality in the Germanspeaking academic community.

The list categorizes journals into 5 levels. A+ (outstanding and leading international academic business research journals), A (leading academic business research journals), B (important and renowned business research journals), C (recognized academic business research journals), and D (academic business research journals).

This list is limited to business areas only and developed for German research community. The use of this list in other countries is not frequent.

\section{CONCLUSION}

In this article, 10 not-for-profit academic journal quality/ranking lists are reviewed. Each list has its own strengths and weaknesses. Considering the above-mentioned comparative analysis, it seems that Norwegian Register for Scientific Journals, Series and Publishers, Chartered Association of Business School's (ABS) Academic Journal Guide, and CARHUS Plus + ranking lists could be used at international level for the journal quality evaluation. On the other side, after conducting review of all above-mentioned lists, the conclusion has been drawn that none of these lists evaluate the journals on the basis of "quality of published articles", "loyalty of editorial board and reviewers with journals", "recognition of journals by other not-for-profit stakeholders", and "authors' experience with journals". Ergo, these not-for-profit lists coincide with for-profit indexing and abstracting entities in this aspect. It's time to give up traditional objective evaluation of journals and interpose some subjective indicators that can serve to refine our search for quality academic journals.

\section{REFERENCES}

Agency for Management of University and Research (2018a). CARHUS PluSt 2018. Retrieved December, 2020, from https://agaur.gencat.cat/en/avaluacio/carhus/

Agency for Management of University and Research. (2018b). CARHUS Plust 2018. Retrieved December, 2020, from https://agaur.gencat.cat/en/avaluacio/carhus/index.html\#bloc4 
Association of Business Schools. (2015). Academic Journal Guide 2016: Introduction and Methodology. Retrieved December, 2020, from https://charteredabs.org/wp-content/uploads/2016/06/AJG105_Methodology.pdf

Australian Business Deans Council (2019). ABDC Journal Quality List. Retrieved December, 2020, from https://abdc.edu.au/research/abdc-journal-list-2/

Australian Business Deans Council. (2016). ABDC Journal Quality List Initial Interim Review Outcomes. Retrieved December, 2020, from https://www.griffith.edu.au/_data/assets/pdf_file/0029/249536/ABDC_Journal_Quality_List_Interim_Review_ Outcomes_as_of_2016.08.02.pdf

Chartered Association of Business Schools. (2020). Academic Journal Guide 2018: Methodology. Retrieved December, 2020, from https://charteredabs.org/wp-content/uploads/2018/03/AJG2018-Methodology.pdf

Danish Agency for Higher Education and Science. (2021). The BF/ lists. Retrieved January, 2021, from https://ufm.dk/en/research-and-innovation/statistics-and-analyses/bibliometric-research-indicator/bfi-lists

Federation of Finnish Learned Societies. (2020). Publication Forum. Retrieved December, 2020, from https://www.julkaisufoorumi.fi/en

Federation of Finnish Learned Societies. (2021). Publication Forum. Retrieved December, 2020, from https://julkaisufoorumi.fi/en/publication-forum

German Academic Association of Business Research. (2019). Liste der Fachzeitschriften in VHB-JOURQUAL3. Retrieved December, 2020, from https://vhbonline.org/vhb4you/vhb-jourqual/vhb-jourqual-3/gesamtliste

Google Scholar. (n.d.). Top publications. Retrieved December, 2020, from https://scholar.google.nl/citations?view_op=top_venues\&hl=en

Harzing, A.W. (2020). Journal Quality List. Retrieved December, 2020, from https://harzing.com/resources/journal-quality-list

Italian National Agency for the Evaluation of the University and Research Systems. (n.d.). Rating of Scientific Journals. Retrieved December, 2020, from https://www.anvur.it/en/homepage/

Krimsky, S. (2013). Do Financial Conflicts of Interest Bias Research?: An Inquiry into the "Funding Effect" Hypothesis. Science, Technology \& Human Values, 38(4): 566-587. doi:10.1177/0162243912456271

Norwegian Centre for Research Data. (2019). Norwegian Register for Scientific Journals, Series and Publishers. Retrieved December, 2020, from https://dbh.nsd.uib.no/publiseringskanaler/Aktuelt_nordic_list_2019-05-14_update

Norwegian Centre for Research Data. (2020). Norwegian Register for Scientific Journals, Series and Publishers. Retrieved December, 2020, from https://dbh.nsd.uib.no/publiseringskanaler/Forside?request_locale=en

Ormans, L. (2016). 50 Journals used in FT Research Rank. Retrieved December, 2020, from https://www.ft.com/content/3405a512-5cbb-11e1-8f1f-00144feabdc0

Vogel, R., Hattke, F., \& Petersen, J. (2017). Journal rankings in management and business studies: What rules do we play by? Research Policy, 46(10): 1707-1722. https://doi.org/10.1016/j.respol.2017.07.001. 